Document downloaded from:

http://hdl.handle.net/10251/60317

This paper must be cited as:

Periche Santamaría, A.; Castelló Gómez, ML.; Heredia Gutiérrez, AB.; Escriche Roberto, MI. (2015). Influence of drying method on steviol glycosides and antioxidants in Stevia Rebaudiana leaves. Food Chemistry. 172:1-6. doi:10.1016/j.foodchem.2014.09.029.

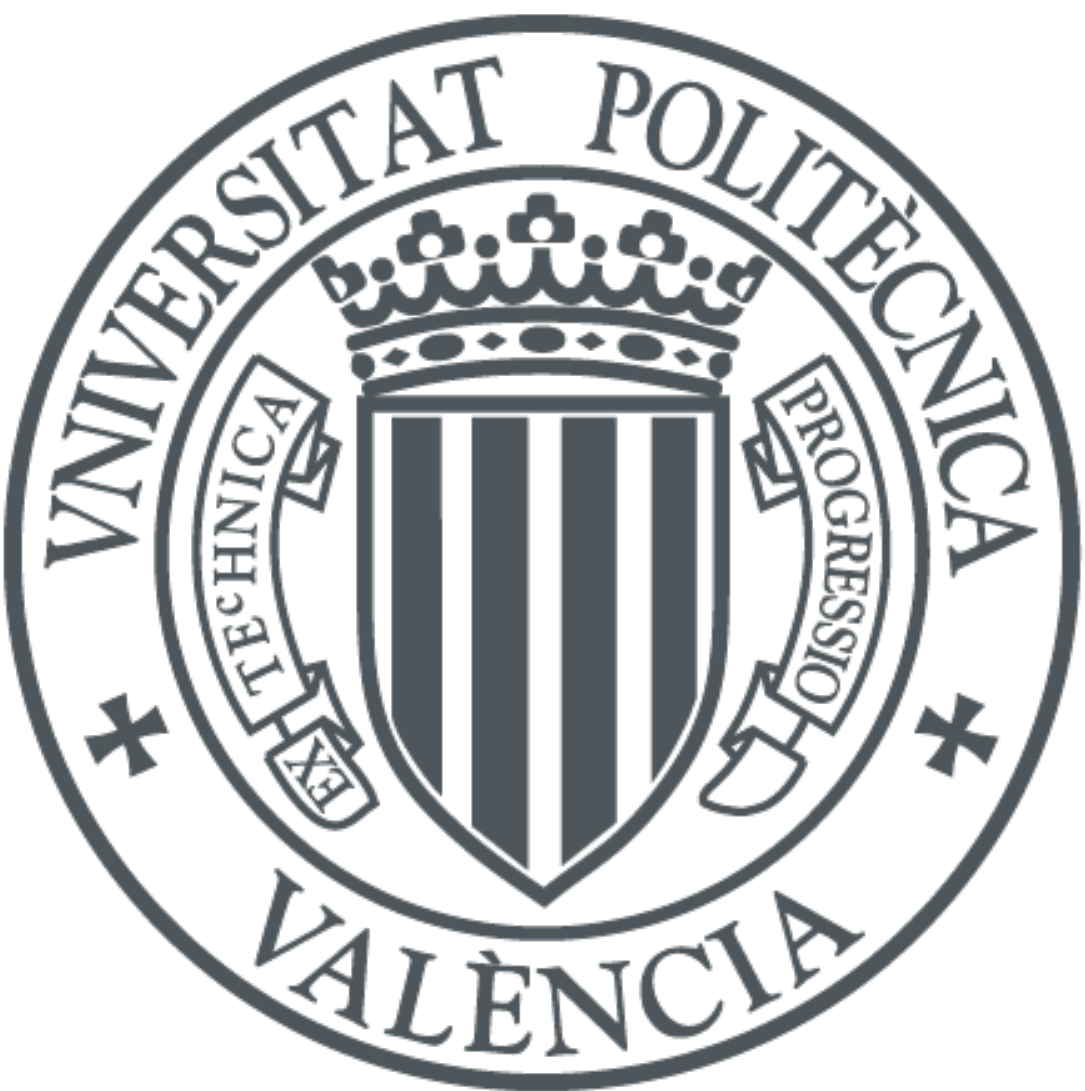

The final publication is available at

http://dx.doi.org/10.1016/j.foodchem.2014.09.029

Copyright Elsevier

Additional Information 


\section{Influence of Drying Method on Steviol Glycosides and Antioxidants in Stevia}

\section{Rebaudiana Leaves}

Angela Periche, María Luisa Castelló, Ana Heredia, Isabel Escriche*

Institute of Food Engineering for Development, Food Technology Department, Universitat

Politècnica de València, P.O.Box:46022, Valencia, Spain

Corresponding author: iescrich@tal.upv.es Tel: +34963873661. Fax: +34963877956

\section{Abstract}

The application of different drying conditions (hot air drying at $100^{\circ} \mathrm{C}$ and $180^{\circ} \mathrm{C}$, freeze drying and shade drying) on steviol glycosides (stevioside, dulcoside A, rebaudioside A and rebaudioside C) and antioxidants in Stevia leaves was evaluated. Stevioside, the major glycoside found in fresh leaves $(81.2 \mathrm{mg} / \mathrm{g})$, suffered an important reduction in all cases, although shade drying was the least aggressive treatment. Considering the antioxidant parameters (total phenols, flavonoids and total antioxidants), the most suitable drying method was hot air at $180^{\circ} \mathrm{C}$, since it substantially increased all of them $(76.8 \mathrm{mg}$ gallic acid, $45.1 \mathrm{mg}$ catechin and $126 \mathrm{mg}$ Trolox, all equivalent/g Stevia, respectively), with respect to those present in fresh leaves (44.4, 2.5 and $52.9 \mathrm{mg}$ equivalent/g). Therefore, the ideal method for drying Stevia leaves depends on their final use (sweetener or antioxidant), although, hot air at $180^{\circ} \mathrm{C}$ is the most recommendable if only one treatment has to be chosen.

Keywords: steviol glycosides, antioxidants, total phenols, total flavonoids, freeze drying, shade drying, hot air drying.

\section{Introduction}

The food industry is increasingly interested in replacing artificial sweeteners with other natural sugars in order to offer the consumer a wider range of choice, and to satisfy the 
requirements of a segment of the population that does not want to or cannot eat sucrose. Stevia leaves (Stevia rebaudiana) have been used as a sweetener in South America for centuries, and nowadays its consumption all over the world. In fact, it is 300 times sweeter than sucrose, with the additional advantages of having: zero calories, zero carbohydrates, and not causing spikes in blood sugar levels. The sweetness of this plant is due to the presence of diterpenes such as steviol glycosides: stevioside (4-13\%), rebaudioside A (2-4\%), rebaudioside C (1-2\%), dulcoside A (0.4-0.7\%), and other less abundant types such as steviolmonoside, rubusoside, steviolbioside, rebaudioside B and rebaudioside F (LemusMoncada, Vega-Gálvez, Zura-Bravo, \& Ah-Hen, 2012). The acceptable daily intake (ADI) for these compounds is 4 mg per kg bodyweight per day (JECFA 2008). The European Food Safety Authority recognized the safety of Stevia leaf extracts for alimentary use in November 2011(EFSA 2011).

Recently there has been an upsurge of interest in the therapeutic potential of plants, as antioxidants in reducing free radical induced tissue injury (Shukla, Mehta, Menta, \& Bajpai, 2012). Stevia leaves are increasingly consumed as infusions due to their antioxidant properties, which stem from their high levels of flavonoids and phenolic compounds. Muanda, Soulimani, Diop and Dicko (2011) identified 18 phenolic compounds which demonstrated the high antioxidant capacity of Stevia leaves. Periche, Koutsidis, and Escriche (2014) found high levels of total phenols and flavonoids in Stevia infusions. CarbonellCapella, Barba, Esteve and Frígola (2013) incorporated extracts of Stevia as a natural source of antioxidants to obtain low-calorie fruit extracts with antioxidant and antimicrobial activity. Like other kinds of herbal teas, Stevia leaves need to be dried for conservation and consumption purposes. Thanks to the drying process two goals are reached, on one hand the growth of microorganisms is prevented and on the other hand storage and transportation is facilitated (Lin, Sung, \& Chen, 2011). Dehydration of plants can be carried out using different methods. Capecka, Mareczek and Leja (2005) demonstrated the efficacy of shade drying (the 
simplest and cheapest method) for leaves of the Lamiaceae species. Chan et al. (2009) used hot air to accelerate the process of drying leaves for ginger species, while Pinela, Barros, Carvalho and Ferreira (2011) did the same for Fabaceae species.

A newer technique using freeze drying (Lin et al. 2011) has been proved to better preserve the quality of medicinal plants (Abascal, Ganora, \& Yarnell, 2005) although the cost is considerably higher than hot air drying.

It is important to highlight that the different drying techniques can influence the composition of some characteristic compounds present in different herbal teas. In this respect, Lin et al. (2011) obtained better results for the antioxidant capacity and total phenol values when the leaves of Echinacea purpurea were freeze dried, than when they were dehydrated with hot air. Pinela et al. (2011) also obtained larger amounts of antioxidants when leaves of the Genista sp. were freeze dried, in comparison with shade drying. On the contrary, Hossain, Barry-Ryan, Martin-Diana and Brunton (2010) obtained less antioxidants from leaves of the Lamiaceae family applying freeze drying than hot air drying.

Clearly, there is a great discrepancy about the extraction of active compounds from herbal teas according to the different drying techniques applied (Lewicki, 2006). Moreover, as far as the authors know, there is no research related to the influence of different drying methods on the antioxidants and steviol glycosides of Stevia leaves. For this reason, the aim of this study was to evaluate how the drying method (shade drying, hot air drying and freeze drying) affects steviol glycosides and antioxidants (total phenols, flavonoids and antioxidant capacity) in Stevia leaves.

\section{Material and Methods}

\subsection{Stevia samples and drying conditions}

Organically produced Stevia rebaudiana leaves from Valencia (Spain) were used in this study. Four different drying conditions were used: shade drying at $20^{\circ} \mathrm{C}$ for 30 days, hot air 
drying at $100^{\circ} \mathrm{C}$ and $180^{\circ} \mathrm{C}$ for 3 minutes in a convective drier, and freeze drying at a vacuum pressure of $9.5 \times 10^{-1} \mathrm{~mm} \mathrm{Hg}$ for 24 hours.

\subsection{Steviol glycosides analysis}

\subsubsection{Steviol glycoside extraction procedure}

The Stevia leaves (fresh or dried leaves) were ground in a grinding mill (A11 Basic, IKA, Germany), and $100 \mathrm{mg}$ of Stevia leaves were shaken in $10 \mathrm{~mL}$ of ethanol/water $(6: 4 \mathrm{v} / \mathrm{v})$ for 5 minutes. The mixture was sonicated for 10 minutes and then centrifuged at $5000 \mathrm{x} \mathrm{g}$ for 5 minutes. An aliquot of $0.5 \mathrm{~mL}$ of the alcoholic extract was diluted with water $(2.5 \mathrm{~mL})$. This solution was loaded on a $3 \mathrm{~mL}$ Strata SPE cartridge (500 mg, $55 \mu \mathrm{m}, 70 \AA$, StrataC18-E Phenomenex, Torrance, CA) pre-activated with methanol $(3 \mathrm{~mL})$ and washed with water (3 $\mathrm{mL}$ ). Then, the SPE cartridge was washed with $3 \mathrm{~mL}$ of water, followed by $3 \mathrm{~mL}$ of acetonitrile in water $(2: 8 \mathrm{v} / \mathrm{v})$; and then air dried for 2 minutes. Finally, the steviol glycosides were eluted from the cartridge with $5 \mathrm{~mL}$ of $80 \%$ acetonitrile in water (Woelwer-Rieck, Lankes, Wawrzun, \& Wüst 2010). The eluate was subjected to LC-MS-MS analysis.

\subsubsection{Methodology}

A LC-MS-MS method (HPLC system coupled to an Agilent 6410 triple quadrupole mass spectrometer, Agilent Technologies Inc., CA, USA) was used in this study for the analysis of the steviol glycosides. Chromatographic separation was carried out in gradient mode by Zorbax SB-C18 column $(50 \mathrm{~mm} \times 2.1 \mathrm{~mm}, 1.8 \mu \mathrm{m})$. The temperature was maintained at $40^{\circ} \mathrm{C}$, with a mobile phase of $10 \mathrm{mM}$ aqueous ammonium acetate (A) and acetonitrile (B). Binary gradient conditions were used: starting with, $7 \% \mathrm{~B}$, held for 0.2 min: linear gradient to $20 \% \mathrm{~B}$ at $0.3 \mathrm{~min}$ and then to $48 \% \mathrm{~B}$ at $5 \mathrm{~min}$; increased to $100 \% \mathrm{~B}$ at $5.1 \mathrm{~min}$ and held until $7 \mathrm{~min}$; followed by a linear gradient to initial conditions at $7.1 \mathrm{~min}$ and a final hold at this composition until $9 \mathrm{~min}$. The flow-rate and injection volume were $0.4 \mathrm{~mL} / \mathrm{min}$. and $5 \mu \mathrm{L}$, respectively. The electrospray was in negative ion mode. Choi et al. (2002) stated that negative ion mode is 10 times more sensitive than positive ion mode. The ionization source 
conditions were: temperature of the drying gas $\left(\mathrm{N}_{2}\right) 325^{\circ} \mathrm{C}$ to $11 \mathrm{~L} / \mathrm{min}$, nebulizer pressure of 50 psi and capillary voltage of $4000 \mathrm{~V}$. Identification and quantification of steviol glycosides in the samples and the standards were performed using the multiple reaction monitoring mode (MRM).

The stock standard solutions of steviol glycosides (stevioside, steviolbioside, rebaudioside A, rebaudioside C, dulcoside A standards (purity > 98\%), Chromadex (CA, USA) were prepared by weighing the appropriate amount of the pure standard and diluting it with methanol to obtain a final concentration of $1 \mathrm{mg} / \mathrm{mL}$. The working standard solution had a concentration of $0.01 \mathrm{mg} / \mathrm{mL}$ in water. The stock standard solution was stored at $20^{\circ} \mathrm{C}$ and the working standard solution at $4^{\circ} \mathrm{C}$.

Quantification was carried out by means of calibration curves obtained from standard solutions $(0.5-10 \mu \mathrm{g} / \mathrm{mL})$. Samples were spiked in order to verify the absence of a matrix effect in the analysis. To ensure the quality of the results and evaluate the stability of the proposed method, an internal quality control (a standard solution) was injected as a first step before each batch of the sample.

\subsection{Validation of the steviol glycosides analysis method}

The validation of the steviol glycosides analytical methodology was carried out according to the guidelines established by EU Commission Decision (2002). To this end, the parameters: linearity, accuracy and precision (repeatability and reproducibility) were studied. The accuracy of the method was established through recovery studies and the precision was verified by intraday precision or repeatability $\left(\mathrm{RSD}_{\mathrm{r}}\right)$ and interday precision or reproducibility $\left(\mathrm{RSD}_{\mathrm{R}}\right)$. Limit of detection (LOD) and limit of quantification (LOQ) were defined as the amount of analyte for which signal-to-noise ratios $(\mathrm{S} / \mathrm{N})$ were higher than 3 and 10 respectively.

\subsection{Determination of total phenolic content}


Total phenolic determination was realized with spectrophotometry (JASCO V-630) using the modified Folin-Ciocalteu method (Sakanaka, Tachibana, \& Okada, 2004). Distilled water (0.5 $\mathrm{mL}$ ), $0.125 \mathrm{~mL}$ of the infusion sample and $0.125 \mathrm{~mL}$ of Folin-Ciocalteu reagent (SigmaAldrich, Germany) were mixed and shaking. After six minutes, $1.25 \mathrm{~mL}$ of a $7 \%$ sodium carbonate solution and $1 \mathrm{~mL}$ of distilled water were added. After $90 \mathrm{~min}$, the absorbance was measured at $760 \mathrm{~nm}$. A blank was considered in this analysis. The quantification was carried out considering a standard curve of gallic acid, expressing the results as mg of gallic acid equivalent per gram of dry matter. The fresh weight of the all fresh samples was converted into dry weight, on the basis of their respective moisture contents and then the dry weight was used for calculation.

\subsection{Determination of total flavonoid content}

Total flavonoid content was analyzed with colorimetry as described by Dewanto, Wu, Adom and Liu (2002). The infusion sample $(0.25 \mathrm{~mL})$, distilled water $(1 \mathrm{~mL})$ and sodium nitrite solution at $5 \%(0.075 \mathrm{~mL})$ were mixed in a cuvette. After $6 \mathrm{~min}$, a $10 \%$ aluminum chloride solution $(0.15 \mathrm{~mL})$ and $1 \mathrm{M}$ sodium hydroxide solution $(0.5 \mathrm{~mL})$ was mixed and left to settle for $5 \mathrm{~min}$. Finally, distilled water $(2 \mathrm{~mL})$ was added and the absorbance was measured at 510 nm straightaway. A blank was considered in this analysis. The quantification was carried out considering a standard curve of $(+)$-catechin (Sigma-Aldrich, Germany) and the results were expressed as mg of (+)-catechin equivalent per gram of dry matter, as was explained above.

\subsection{Determination of total antioxidant capacity}

The antioxidant activity (AA) was measured based on of the scavenging activities of the stable 2,2-diphenyl-1-picrylhydrazyl (Sigma-Aldrich, Germany) free radical as described by Shahidi, Liyana-Pathirana and Wall (2006), with some modifications. Accordingly, $0.1 \mathrm{~mL}$ of the infusion sample (diluted in methanol:water (80:20)) was mixed with $3.9 \mathrm{~mL}$ of a methanolic solution of DPPH $(0.025 \mathrm{mg} / \mathrm{mL}$, prepared in methanol:water $(80: 20))$. The solution was shaken, after $30 \mathrm{~min}$ the absorbance of the samples were measured at $515 \mathrm{~nm}$ 
using methanol as a blank. The quantification was calculated with a standard curve of Trolox (6-Hydroxy-2,5,7,8-tetramethylchroman-2-carboxylic acid). The results were expressed as mg of Trolox equivalent per gram of dry matter, as explained previously.

\subsection{Statistical analysis}

An ANOVA (Statgraphics Centurion) was used to study the influence of the treatments on the steviol glycosides, antioxidants, phenols and flavonoids. In this analysis, the homogenous groups indicate statistical differences between types of treatment $(\alpha=99 \%)$. A Principal Component Analysis (PCA) was also performed using the software Unscrambler X.10 to describe the relationships between the treatments and the variables analysed.

\section{Results and Discussion}

\subsection{Validation of the steviol glycosides analytical methodology.}

An external standard calibration curve was made using standard solutions with final concentration levels of: $0.5,1,2,5,7$ and $10 \mu \mathrm{g} / \mathrm{mL}$, with the aim of obtaining the linearity value. For each level, six replicates were made. The linearity response from 0.5 to $10 \mu \mathrm{g} / \mathrm{mL}$ was $\mathrm{R}^{2} \geq 0.995$.

The recovery studies were carried out by adding known quantities of steviol glycosides to a sample $(1,5$ and $10 \mu \mathrm{g} / \mathrm{g})$. Six replicates of all the spiked sample levels were analyzed. The method used permitted recovery of steviol glycosides between $70.5 \%$ (for steviolbioside at 10 $\mu \mathrm{g} / \mathrm{g}$ level) and $105.6 \%$ (for rebaudioside $\mathrm{A}$ at $5 \mu \mathrm{g} / \mathrm{g}$ level) for the concentration range studied. The standard deviation corresponding to recovery values was less than $20 \%$ in all cases (ranging from 4.0 to 18), proving that the analytical method was accurate.

Repeatability or Intra-day precision $\left(\mathrm{RSD}_{\mathrm{r}}\right)$ (carried out by the same operator on the same day) was evaluated by performing the assay (on six replicates of fortified Stevia samples) at three levels: 1,5 and $10 \mu \mathrm{g} / \mathrm{g}$. These values ranged from $1.7 \%$ for dulcoside A to $14.6 \%$ for steviolvioside. Reproducibility or inter-day precision $\left(\mathrm{RSD}_{\mathrm{R}}\right)$ (carried out by 2 different operators on 3 consecutive days) ranged from $5.2 \%$ for dulcoside $\mathrm{A}$ to $16.5 \%$ for 
steviolbioside. These RSD values are in total agreement with EU Commission Decision (2002) requirements, since they were always lower than $20 \%$ for all the concentration levels assayed.

The limits of detection (LOD) were: $0.05 \mu \mathrm{g} / \mathrm{g}$ (dulcoside A), $0.11 \mu \mathrm{g} / \mathrm{g}$ (rebaudioside A), $0.09 \mu \mathrm{g} / \mathrm{g}$ (rebaudioside C), $0.04 \mu \mathrm{g} / \mathrm{g}$ (stevioside) and $0.14 \mu \mathrm{g} / \mathrm{g}$ (steviolbioside); and the limits of quantification (LOQ) were: $0.15 \mu \mathrm{g} / \mathrm{g}$ (dulcoside A), $0.32 \mu \mathrm{g} / \mathrm{g}$ (rebaudioside A), $0.31 \mu \mathrm{g} / \mathrm{g}$ (rebaudioside C), $0.15 \mu \mathrm{g} / \mathrm{g}$ (stevioside) and $0.49 \mu \mathrm{g} / \mathrm{g}$ (steviolbioside).

From the results of these validation parameters, it can be concluded that the methodology applied in this work is appropriate to guarantee the quantitative values of steviol glycosides obtained in the Stevia leaves analyzed.

\subsection{Influence of drying method on the steviol glycosides.}

Figure 1 shows the average values and the standard deviation of the 4 steviol glycosides (dulcoside $\mathrm{A}$, rebaudioside $\mathrm{A}$, rebaudioside $\mathrm{C}$ and stevioside) identified and quantified in fresh, and dried Stevia leaves obtained applying different drying conditions (hot air drying at $100^{\circ} \mathrm{C}$ and $180^{\circ} \mathrm{C}$, freeze drying and shade drying). All values are expressed in $\mathrm{mg}$ of compounds per gram of dry matter. Additionally, this figure shows the homogenous groups of the ANOVA carried out for the factor "drying method" for every compound. The F-ratio values were: 49.84, 5.31, 7.22 and 87.52 for dulcoside $\mathrm{A}$, rebaudioside $\mathrm{A}$, rebaudioside $\mathrm{C}$ and stevioside, respectively. These values reflect the greater influence of the drying method on dulcoside A and stevioside than the other two compounds.

In contrast to other studies (Cacciola, Delmonte, Jaworska, Dugo, Mondello \& Rader, 2011), steviolbioside was not found in any sample in this work. In fact, this is logical since this compound, like rebaudioside B, is not a native constituent of Stevia rebaudiana, however, in some cases they may appear as artifacts during the extraction process (Kennelly 2002; Prakash, Dubois, Clos, Wilkens \& Fosdick, 2008). 
By far the most abundant steviol glycoside in fresh leaves was stevioside $(81.2 \pm 9.3 \mathrm{mg} / \mathrm{g})$, followed by rebaudioside C $(3.8 \pm 0.3 \mathrm{mg} / \mathrm{g})$, dulcoside $\mathrm{A}(2.8 \pm 0.5 \mathrm{mg} / \mathrm{g})$ and rebaudioside A $(3.5 \pm 0.3 \mathrm{mg} / \mathrm{g})($ Fig. 1$)$.

With respect to the results obtained when the leaves were dehydrated, it can be observed that rebaudioside $\mathrm{A}$ and rebaudioside $\mathrm{C}$ showed very low concentration values in all the conditions applied, ranging from $0.5 \pm 0.14 \mathrm{mg} / \mathrm{g}$ (in shade drying) to $6.1 \pm 1.6 \mathrm{mg} / \mathrm{g}$ (in hot air to $180^{\circ} \mathrm{C}$ drying), and from $2.1 \pm 0.6 \mathrm{mg} / \mathrm{g}$ (hot air to $100^{\circ} \mathrm{C}$ drying) to $3.6 \pm 0.7 \mathrm{mg} / \mathrm{g}$ (in shade drying), respectively. For these compounds, as Figure 1 shows, there were practically no differences between fresh and dehydrated leaves, even though the ANOVA analyses found different homogeneous groups. However, different behavior was observed in the case of stevioside and dulcoside A, for dehydrated samples. For both compounds, the highest values in the treated samples were obtained for shade drying. In the case of stevioside an important decrease occurred as a consequence of all the drying treatments applied, in comparison to the levels obtained in the fresh samples. For this compound there were no significant differences between shade drying $(48 \pm 12 \mathrm{mg} / \mathrm{g})$, hot air drying at $180^{\circ} \mathrm{C}(37 \pm 6 \mathrm{mg} / \mathrm{g})$ and freeze drying $(35 \pm 8 \mathrm{mg} / \mathrm{g})$. There is no information in the literature relating the behavior of steviosides and the air drying temperature. However, some authors reported that an increase in extraction temperature in combination with solvents results a higher yield of this compound. Specifically, Pól et al (2007) found that a temperature of $160^{\circ} \mathrm{C}$ resulted in a $20 \%$ increase compared to $110^{\circ} \mathrm{C}$. Meanwhile, the behavior of dulcoside A was very different to the other three compounds showing a significant increase in yield as a consequence of the shade drying and the freeze drying treatments in comparison to the fresh sample, reaching $22.3 \pm 1.9 \mathrm{mg} / \mathrm{g}$ and $14.1 \pm 3.5 \mathrm{mg} / \mathrm{g}$, respectively. The increase in the concentration as a consequence of using freeze drying and shade drying is not surprising as this is seen with other compounds such as phenols and flavonoids. This was observed in this study (section 3.2) and also by other 
authors (Chan et al. 2009; Hossain et al. 2010; Hamrouni-Sellami, Rahali, Rebey, Bourgou, Limam, \& Marzouk, 2013).

The research data reported by other authors about the concentration of the different steviol glycosides in dried Stevia leaves vary greatly, and in some occasions do not provide information about the drying method applied. One of the most recent works is by WoelverRieck et al. (2010) who obtained $79 \pm 2.9 \mathrm{mg} / \mathrm{g}$ and $77.8 \pm 6.1 \mathrm{mg} / \mathrm{g}$ of stevioside and $49.3 \pm 4.4$ $\mathrm{mg} / \mathrm{g}$ and $42.8 \pm 2.9 \mathrm{mg} / \mathrm{g}$ of rebaudioside A, in Stevia dried leaves grown in two different types of soil, fertile sandy loam and light loamy soil, respectively. The values for stevioside are similar to those obtained in this work, however for rebaudioside A they are much higher.

Moreover, Shafii, Vismeh, Beaudry, Warner and Jones (2012) found from 2 to $125 \mathrm{mg} / \mathrm{g}$ of stevioside, from 2.5 to $164 \mathrm{mg} / \mathrm{g}$ of rebaudioside A and from 1.5 to $125 \mathrm{mg} / \mathrm{g}$ of rebaudioside C in 1,100 Stevia leaf extracts. Gardana, Scaglianti and Simonetti (2010) reported $5.8 \mathrm{~g}$ of stevioside, $1.8 \mathrm{~g}$ of rebaudioside $\mathrm{A}, 1.3 \mathrm{~g}$ of rebaudioside $\mathrm{C}$ and $0.7 \mathrm{~g}$ of dulcoside $\mathrm{A}$ in $100 \mathrm{~g}$ of Stevia.

\subsection{Influence of drying method on the antioxidants.}

The average values and the standard deviation of total phenols (mg gallic acid equivalent/g Stevia), flavonoids (mg of catechin equivalent/g Stevia) and total antioxidants (mg Trolox equivalent/g Stevia) quantified in fresh, and dried Stevia leaves obtained applying the different drying methods, are shown in Fig. 2. The ANOVA homogenous groups are indicated by letters in this figure.

In fresh leaves the amount of phenols, flavonoids and antioxidants were: $44.40 \pm 1.04 \mathrm{mg}$ gallic acid equivalent/g Stevia, $2.52 \pm 0.24 \mathrm{mg}$ catechin equivalent/g Stevia and $52.92 \pm 0.84 \mathrm{mg}$ Trolox equivalent/g Stevia, respectively. It is noteworthy that drying treatments caused an increase in the content of flavonoids and antioxidants when compared with fresh leaves.

In contrast to the steviol glycosides, phenols, flavonoids and antioxidants exhibited similar behaviour as a consequence of the application of the different drying conditions. The highest 
values for the three parameters (total phenols, flavonoids and antioxidants) were found for hot air drying at $180^{\circ} \mathrm{C}(76.8,45.1$ and $126 \mathrm{mg}$ equivalent/g), followed by shade drying (39.1, $20.3,75.9 \mathrm{mg}$ equivalent/g), hot air drying at $100^{\circ} \mathrm{C}(31.5,17.2,64.9 \mathrm{mg}$ equivalent $/ \mathrm{g})$, and finally freeze drying $(26.2,9.9,48.5 \mathrm{mg}$ equivalent/g), respectively. This last treatment showed the lowest values, thus being the least suitable treatment for the extraction of antioxidants.

The high content of flavonoids is due to the presence of flavonols and flavones in Stevia leaves. Ghanta, Banerjee, Poddar and Chattopadhyay (2007) isolated 6 flavonoids (quercetin3-O- $\beta$-D-arabinoside, quercetin-3-O- $\beta$-D-rhamnoside, kaempherol-3-O-rhamnoside, apigenin, apigenin-4-O- $\beta$-D-glycoside, luteolin) and Cacciola et al. (2011) 4 different ones (quercetin3-O-glucoside, quercetin-3-O-rutinoside, apigenin-7-O- $\beta$-D-glycoside, luteolin-7-O- $\beta$-Dglycoside). In this work, the flavonoid content was higher for all drying methods applied in comparison to fresh leaves. This result could be related to an increase in the extractability of such compounds as a consequence of the matrix changes during the drying process. As observed in the present work, Hamrouni-Sellami et al. (2013) also obtained higher values of total flavonoids in dried leaves of S. Officinalis than in fresh plants. However, in contrast to the present study, Ferreira and Luthria (2010), obtained lower levels of antioxidant capacity (in dried Artemisia annua L. leaves) for shade drying than hot air drying. In the case of phenols, in this study, hot air drying at $180^{\circ} \mathrm{C}$ and fresh leaves showed the highest values, respectively. Capecka et al. (2005) also obtained lower levels of phenols for shade dried leaves (in Lemon balm leaves) than the fresh ones.

There are some works in the literature regarding the levels of total phenol, flavonoids and antioxidant activity in dried Stevia leaves, however, very few studies specify the drying method. For instance, in the case of phenols: $25.18 \mathrm{mg}$ gallic acid/g (Tadhani, Patel, \& Subhash, 2007); $56.74 \mathrm{mg}$ gallic acid/g, obtained with air drying (Shukla et al. 2012); $0.86 \mathrm{mg}$ gallic/mg with shade drying (Ghanta et al. 2007) and $130.67 \mathrm{mg}$ catechin $/ \mathrm{g}$, air drying at $40^{\circ} \mathrm{C}$ 
for $12 \mathrm{~h}$ (Kim, Yang, Lee \& Kang, 2011). In the case of total flavonoids: $21.73 \mathrm{mg}$ gallic acid/g (Tadhani et al. 2007); $0.83 \mathrm{mg}$ quercetin/mg (Ghanta et al. 2007); $15.64 \mathrm{mg}$ quercetin/g (Kim et al. 2011) and $20.68 \mathrm{mg}$ catechin/g drying room temperature (Muanda et al. 2011), and finally, for antioxidant activity: $38.24 \mathrm{mg}$ trolox/g (Tadhani et al. 2007) and 8.72mg gallic acid/g (Abou-Arab, Abou-Arab, \& Abu-Salem, 2010).

\subsection{Global behavior of antioxidants and steviol glycosides.}

A PCA was applied in order to appreciate the overall effect that the drying method had on steviol glycosides and antioxidants together. The corresponding bi-plot obtained (scores "treatments" and loading "variables") is shown in Fig. 3 (PC1 explained $46 \%$ of the total variance and PC2, $25 \%$ ). The proximity between variables indicates the correlation between them, and in the case of drying treatments similar behavior. This figure shows more clearly that the two groups of variables (antioxidants and glycosides of steviol) show in general opposing behavior with respect to the effect of the drying treatments applied. That is to say, the hot air drying treatment at $180^{\circ} \mathrm{C}$ is placed at the far end of the right axis in the figure, which corresponds to the highest values of the three antioxidant parameters (total phenols, flavonoids and total antioxidants) and the lowest of the steviol glycosides. On the contrary, fresh and shade drying are placed on the opposite side (left axis), which corresponds to the highest content of steviol glycosides (especially dulcoside A, rebaudioside C and stevioside) and the lowest level of all the antioxidant parameters. As it can been observed, not a single drying treatment permits the maximum extraction of all the compounds together.

\section{Conclusions}

The drying conditions applied in fresh Stevia leaves have a great impact on the extraction of steviol glycosides and antioxidants. In general, the yield of these compounds was affected in different ways according to the drying conditions (hot air drying at $100^{\circ} \mathrm{C}$ and $180^{\circ} \mathrm{C}$, freeze drying and shade drying). The drying conditions produced an important increase in antioxidant capacity but an important decrease in the principal steviol glycoside (stevioside) 
which diminished with all treatments, especially with hot air at $100^{\circ} \mathrm{C}$. For this compound, there were no significant differences between the other treatments, although shade drying produced the highest values of this compound. Dulcoside A increased only with the shade and freeze drying treatments. On the other hand, the levels of the less abundant glycosides (rebaudioside A and rebaudioside C) changed very little when comparing fresh and dehydrated leaves. Considering all the steviol glycosides, the least aggressive treatment was shade drying.

With respect to the antioxidant parameters (total phenols, flavonoids and total antioxidants), the most suitable drying method was hot air at $180^{\circ} \mathrm{C}$, since it was able to substantially increase the level of all of them compared to the fresh Stevia leaves.

Therefore, the optimum drying conditions for fresh Stevia leaves is determined by whether they are used for sweetening or for their antioxidant properties. Although, if one treatment had to be chosen, hot air drying at $180^{\circ} \mathrm{C}$ is the most recommendable overall.

As drying methods are known to be highly effective in the extraction of antioxidants, the profile of specific antioxidant compounds should be studied in greater depth.

\section{Acknowledgements}

The authors thank the Universitat Politècnica de València (Spain) (for funding the project PAID 2011-ref: 2012 and the PhD scholarship), and the Generalitat Valenciana (Spain) (for the project $\mathrm{GV} / 2013 / 029)$.

\section{References}

Abascal, K., Ganora, L., \& Yarnell, E. (2005). The effect of freeze drying and its implications for botanical medicines: a review. Phytotherapy Research, 19,655-660.

Abou-Arab, A.E., Abou-Arab, A.A., \& Abu-Salem, M.F. (2010). Physicochemical assessment of natural sweeteners steviosides produced from Stevia rebaudiana Bertoni plant. African Journal of Food Science, 4, 269-281. ISSN:1996-0794. 
Cacciola, F., Delmonte, P., Jaworska, K., Dugo, P., Mondello, L., \& Rader, J. (2011). Employing ultra-high pressure liquid chromatography as the second dimension in a comprehensive two-dimensional system for analysis of Stevia rebaudiana extracts. Journal of Chromatography A, 1218, 2012-2018.

Capecka, E., Mareczek, A., \& Leja, M. (2005). Antioxidant activity of fresh and dry herbs of some Lamiaceae species. Food Chemistry, 93, 223-226.

Carbonell-Capella, J.M., Barba, F.J., Esteve, M.J., \& Frígola, A. (2013) High pressure processing of fruit juice mixture sweetened with Stevia rebaudiana Bertoni: Optimal retention of physical and nutritional quality. Innovative Food Science and Emerging Technologies, 18, 48-56.

Chan, E.W.C., Lim, Y.Y., Wong, K.K., Lim, K.K., Tan, S.P., Lianto, F.S., \& Yong, M.Y. (2009). Effects of different drying methods on the antioxidant properties of leaves and tea of ginger species. Food Chemistry, 113, 166-172.

Choi, Y.H., Kim, I., Yoon, K., Lee, S.J., Kim, C.Y., Yoo, K.P., Choi, Y.H., \& Kim, J. (2002). Supercritical fluid extraction and liquid chromatographic-electrospray mass spectrometric analysis of stevioside from Stevia rebaudiana leaves. Chromatographia, 55, 617-620.

Commission Decision 2002/657/EC of 12 August (2002). Implementing Council Directive 96/23/EC concerning the performance of analytical methods and the interpretation of results, OJEC L221, 8-36. Brusels, Belgium.

Dewanto, V., Wu, X., Adom, K.K., \& Liu, R.H. (2002). Thermal processing enhances the nutritional value of tomatoes by increasing total antioxidant activity. Journal of Agricultural and Food Chemistry, 50, 3010-3014.

EFSA. European Food Safety Authority (2011). Revised exposure assessment for steviol glycosides for the proposed uses as a food additive. EFSA Journal 9,1,1972. doi:10.2903/j.efsa.2011.1972 
Ferreira, J.F. \& Luthria, D.L. (2010). Drying Affects Artemisinin, Dihydroartemisinic Acid, Artemisinic Acid, and the Antioxidant Capacity of Artemisia annua L. Leaves. Journal of Agricultural and Food Chemistry, 58, 1691-1698.

Gardana, C., Scaglianti, M., \& Simonetti, P. (2010). Evaluation of steviol and its glycosides in Stevia rebaudiana leaves and commercial sweetener by ultra-high-performance liquid chromatography-mass spectrometry. Journal of Chromatography A, 1217, 1463-1470.

Ghanta, S., Banerjee, A., Poddar, A., \& Chattopadhyay, S. (2007). Oxidative DNA damage preventive activity and antioxidant potential of Stevia rebaudiana (Bertoni) Bertoni, a natural sweetener. Journal of Agricultural and Food Chemistry, 55, 10962-10967.

Hamrouni-Sellami, I., Rahali, F.Z., Rebey, I.B., Bourgou, S., Limam, F., \& Marzouk, B. (2013). Total Phenolics, Flavonoids, and Antioxidant Activity of Sage (Salvia officinalis L.) Plants as Affected by Different Drying Methods. Food and Bioprocess Technology, 6, 806-817.

Hossain, M.B., Barry-Ryan, C., Martin-Diana, A.B., \& Brunton, N.P. (2010) Effect of drying method on the antioxidant capacity of six Lamiaceae herbs. Food Chemistry, 123, 85-91.

JECFA. Joint FAO/WHO Expert Committee on Food Additives (2008) Steviol glycosides. In Compendium of Food Additive Specifications, 69th Meeting, FAO/WHO Monographs 5, Rome, Italy.

Kennelly, E.J., 2002. Sweet and non-sweet constituents of Stevia rebaudiana (Bertoni) Bertoni. In Kinghorn, A.D. (Ed.), Stevia, the genus Stevia. Medicinal and Aromatic Plants - Industrial Profiles, vol. 19 (pp. 68-85). London, UK: Taylor and Francis.

Kim, I., Yang, M., Lee, O., \& Kang, S. (2011). The antioxidant activity and the bioactive compound content of Stevia rebaudiana water extracts. LWT-Food Science and Technology, $44,1328-1332$. 
Lemus-Moncada, R., Vega-Gálvez, A., Zura-Bravo, L., \& Ah-Hen, K. (2012). Stevia rebaudiana Bertoni, source of a high-potency natural sweetener: A comprehensive review on the biochemical, nutritional and functional aspects. Food Chemistry, 132, 1121-1132.

Lewicki, P.P. (2006). Design of hot air drying for better foods. Trends in Food Science and Technology 17, 153-163.

Lin, S.D., Sung, J.M., \& Chen, C.L. (2011). Effect of drying and storage conditions on caffeic acid derivatives and total phenolics of Echinacea Purpurea grown in Taiwan. Food Chemistry, 125, 226-231.

Muanda, F., Soulimani, R., Diop, B., \& Dicko, A. (2011). Study on chemical composition and biological activities of essential oil and extracts from Stevia rebaudiana Bertoni leaves. LWT-Food Science and Technology 44, 1865-1872.

Periche, A., Koutsidis, G., \& Escriche, I. (2014). Composition of antioxidants and amino acids in Stevia leaf infusions. Plant Foods for Human Nutrition, 69, 1-7.

Pinela, J., Barros, L., Carvalho, A.M., \& Ferreira, I. (2011). Influence of the drying method in the antioxidant potential and chemical composition of four shrubby flowering plants from the tribe Genisteae (Fabaceae). Food and Chemical Toxicology, 49, 2983-2989.

Pól, J., Varadová-Ostrá, E., Karáse, P., Roth, M., Benesová, K., Kotlariková, P., \& Cáslavsky, J. (2007). Comparison of two different solvents employed for pressurized fluid extraction of stevioside from Stevia rebaudiana: methanol versus water. Analytical and Bioanalytical Chemistry, 388, 1847-1857.

Prakash, I., Dubois, G.E., Clos, J.F., Wilkens, K.L., \& Fosdick, L.E. (2008). Development of rebaudiana, a natural, non-caloric sweetener. Food and Chemical Toxicology 46, 75-82.

Sakanaka, S., Tachibana, Y., \& Okada, Y. (2004). Preparation and antioxidant properties of extracts of Japanese persimmon leaf tea (kakinoha- cha). Food Chemistry, 89, 569-575.

Shafii, B., Vismeh, R., Beaudry, R., Warner, R., \& Jones, A.D. (2012). Large-scale profiling of diterpenoid glycosides from Stevia rebaudiana using ultrahigh performance liquid 
chromatography/tandem mass spectrometry. Analytical and Bioanalytical Chemistry, 403, 2683-2690.

411

412

413

Shahidi, F., Liyana-Pathirana, C.M., \& Wall, D.S. (2006), Antioxidant activity of white and black sesame seeds and their hull fractions. Food Chemistry, 99, 478-483.

Shukla, S., Mehta, A., Menta, P., \& Bajpai, V. (2012). Antioxidant ability and phenolic content of aqueous leaf extract of Stevia rebaudiana Bert. Experimental and Toxicologic Pathology 64, 807-811.

Tadhani, M., Patel, V., \& Subhash, R. (2007). In vitro antioxidant activities of Stevia rebaudiana leaves and callus. Journal of Food Composition and Analysis, 20, 323-329.

Woelwer-Rieck, U., Lankes, C., Wawrzun, A., \& Wüst, M. (2010). Improved HPLC method for the evaluation of the major steviol glycosides in leaves of Stevia rebaudiana. European Food Research and Technology, 231, 581-588.

\section{Figure captions}

Figure. 1 Average values and the standard deviation of the 4 steviol glycosides (dulcoside A, rebaudioside A, rebaudioside $\mathrm{C}$ and stevioside) in fresh and dried Stevia leaves obtained applying different drying conditions (hot air drying at $100^{\circ} \mathrm{C}$ and $180^{\circ} \mathrm{C}$, freeze drying and shade drying). The ANOVA homogenous groups are indicated by letters

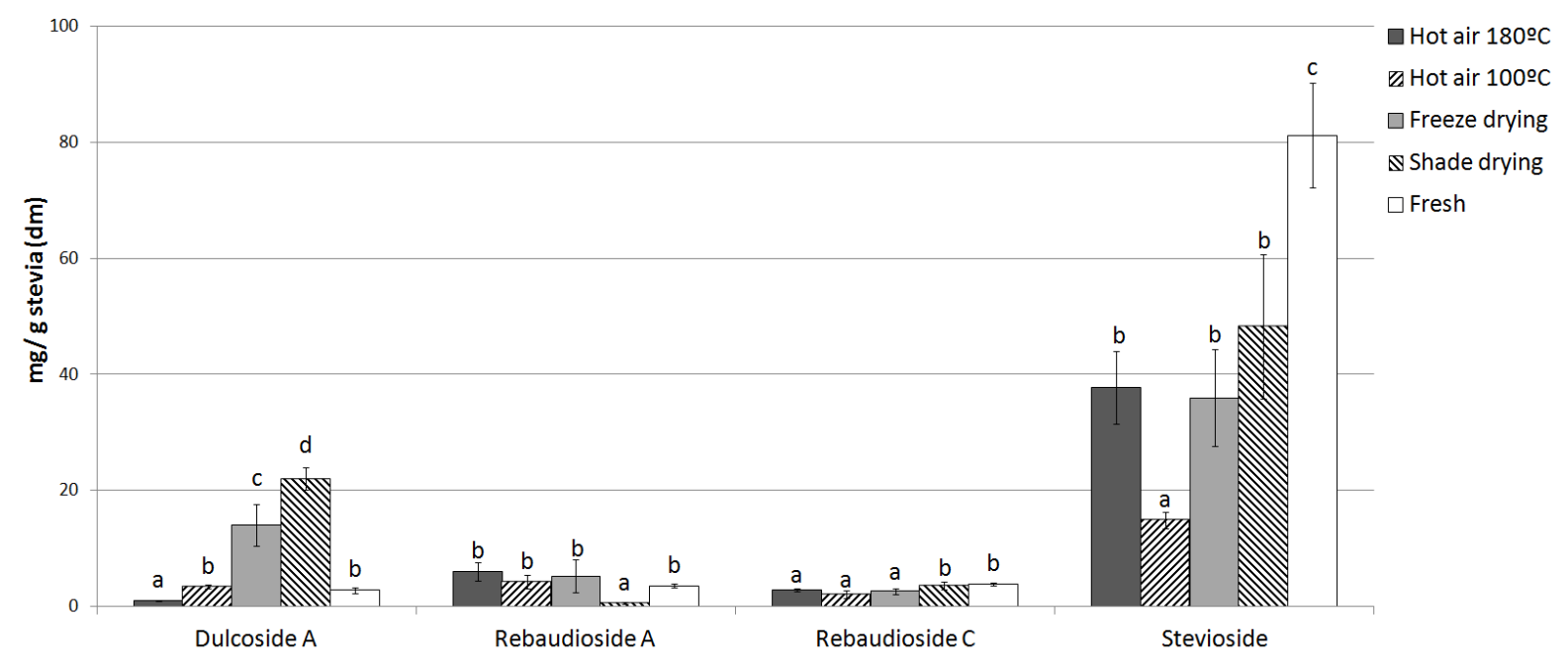


427 Figure. 2 Average values and the standard deviation of total phenols (mg gallic acid equivalent/g Stevia), flavonoids (mg of catechin equivalent/g Stevia) and total antioxidants (mg Trolox equivalent/g Stevia) in fresh and dried Stevia leaves obtained applying the different drying methods (hot air drying at $100^{\circ} \mathrm{C}$ and $180^{\circ} \mathrm{C}$, freeze drying and shade drying). The ANOVA homogenous groups are indicated by letters.

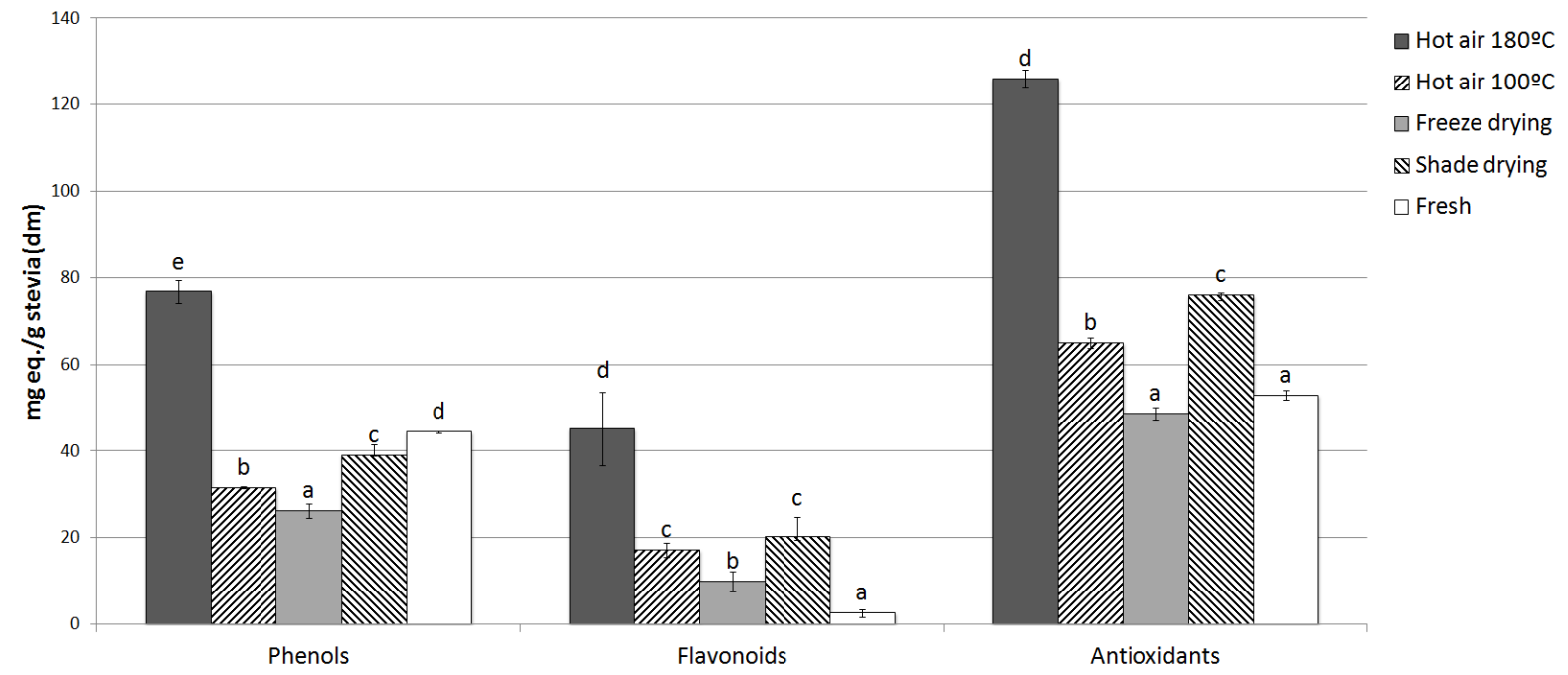

433 Figure. 3 Bi-plot of Principal Components Analysis for the drying treatments (white diamond flavonoids and antioxidant activity) (black diamond $\downarrow$ ).

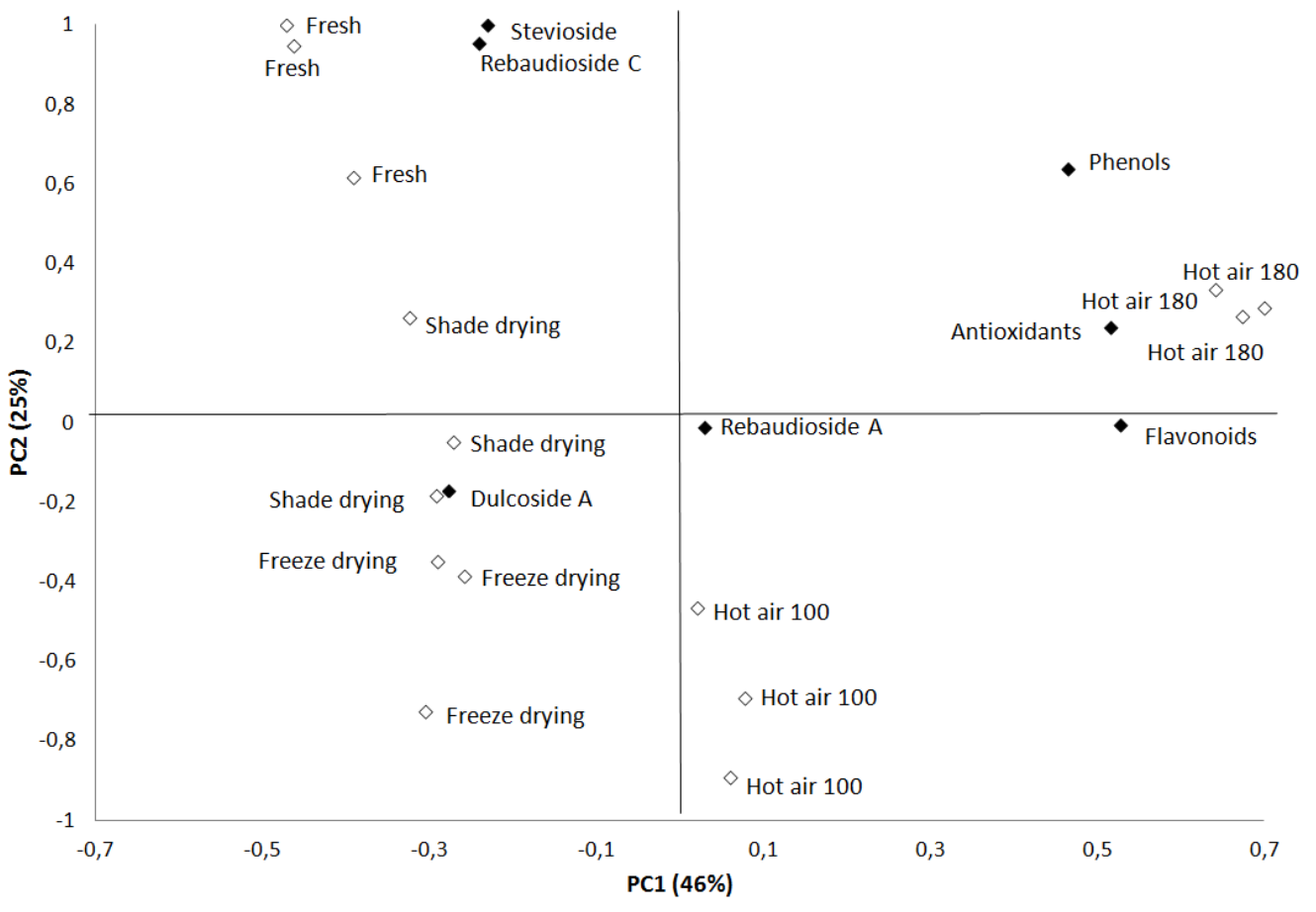

